\section{ambient SCIENCE \\ Vol. 06h(1):36-39 \\ Year 2019}

ORIGINAL ARTICLE

\title{
Demographic Information and Biochemical Variables Helping to Predict the Frequent Kidney and Urinary Tract Stone Factors
}

\author{
Reza Inaloo', Hosein Hakimelahi', Zeinab \\ Ghasemiannezhad Jahromi , Alireza \\ Yousefi ${ }^{1 *}$, Navid Kalani ${ }^{3}$ \\ 'Department of Urology, Jahrom University of Medical Sciences, \\ Jahrom, Iran. \\ ${ }^{2}$ Student Research committee, Jahrom University of Medical \\ Sciences, Jahrom, Iran. \\ ${ }^{2}$ Department of Anesthesiology, Critical care and pain \\ management research center, Jahrom University of Medical \\ Sciences, Jahrom, Iran. \\ Study Area: Jahrom, Iran \\ Coordinates: $28^{\circ} 30^{\prime}{ }^{\circ} 0^{\prime \prime} \mathrm{N}$; $53^{\circ} 33^{\prime} 38: \mathrm{E}$
}

Keywords:

This study is approved by the Ethics committee of the jahrom University of medical sciences,jahrom,Iran

\section{Introduction:}

Urinary stones are formed by pathologic biomineralization processes in the urinary system (Giannossi et al., 2012). Indeed, stones are formed in the kidney and leave the body through urine. Small stones may be passed without signs, but stones more than $5 \mathrm{~mm}$ tend to cause more obstruction and cause severe pain. Some stones do not enter the ureter, instead, they can grow and take the kidney's pelvis, and if they are not treated timely, they can cause kidney damage. Bladder stones have other causes that are usually associated with prolonged urinary retention in the bladder with obstruction resulting from prostate hyperplasia. Bladder stones are much more common in men, and these stones may originate from the bladder itself, but small stones may also form in the kidney and then enter the bladder (Tiselius, 2003; Morgan \& Pearle, 2016). The incidence of kidney stones is varied from 68 to 720 per $1,000,000$ people, depending on the country or region where the studies were conducted (Basiri et al., 2009). In fact, the prevalence of kidney stones has been reported as a common disease with the possibility of $15 \%$ throughout life. It is influenced by many factors such as age, gender, race, and geographical location (Soucie et al., 1996; Basiri et al., 2010). Dietary risk factors also left a different impact on the development of urinary stones based on age and gender. Calcium phytate

\section{Abstract}

Urinary stones are formed by pathologic bio-mineralization processes in the urinary system, affected by many factors such as age, gender, race, and geographical location as well as biochemical factors. This descriptive cross-sectional study was conducted to predict the effective factors in the recurrence of kidney and urinary tract stone in patients visiting Peymanieh Hospital of Jahrom on 116 kidney stone patients. After receiving the patients' demographic data, two urine samples of 24 -hour were taken at two different time intervals after at least one month of the treatment of kidney stone disease. The data analysis was done based on the obtained regression coefficients. The result of Poisson Regression showed that no biochemical parameters $(\mathrm{pH}$, 24-hour urine volume, urinary phosphorus/ creatinine /calcium/ oxalate/sodium/ uric acid/ urea/ magnesium/ chlorine/ citrate or urinary potassium), age, gender and BMI can signif icantly predict the frequent occurrence of kidney and urinary tract stones in patients.

and the use of adequate liquids reduce the risk of urinary stones in young women while animal proteins and sucrose increase this risk. In older adults, calcium intake does not affect stones, however, magnesium, potassium, and liquids reduce the risk of urinary stones, while, vitamin $C$ increases the risk of symptomatic stones (Trinchieri, 2008). Currently, the patients are taking interest to know the cause of kidney stones, but unfortunately, their interests are not always offered in long-term continuity with medical advice or treatment, thus, before starting a broad metabolic work, it must be taken into account how to motivate the patient to perform analytical and therapeutic steps (Pearle et al., 2014). Therefore, the mechanisms for the metabolism of stones that are repeatedly developed in patients should be evaluated to determine the risk factors for kidney stones (Nicoletta \& Lande, 2006). Up to $15 \%$ of people suffer from kidney stones in their life. A simple metabolism assessment, including a 24-hour urine collection, can be sufficient to analyze all the risk factors for developing kidney stones for medical evaluation (Pak et al., 2001). By keeping in mind the above facts and figures, this study was conducted to predict the effective factors in the recurrence of kidney and urinary tract stones based on demographic and biochemical characteristics. 
ORIGINAL ARTICLE

\section{Methodology cum Results:}

Total of 116 patients with kidney and urinary tract stones were enrolled for this study among which $62.1 \%$ were male and $37.9 \%$ were female. Their average age was $14.68 \pm 44.66$ and $47.2 \%$ of patients were of less than 40 years old. Body Mass Index (BMI) of $62.1 \%$ of the participants was normal and $28.4 \%$ of them was overweight. Table-1 \& 2 show descriptive indices of demographic variables in patients.

Table-1: Demographic analysis of the patients

\begin{tabular}{llll}
\hline \multicolumn{2}{l}{ Variables } & Count & $\%$ \\
\hline Sex & male & 72 & $62.1 \%$ \\
& female & 44 & $37.9 \%$ \\
Age & $<30$ & 24 & $20.7 \%$ \\
& $30-40$ & 31 & $26.7 \%$ \\
& $40-50$ & 23 & $19.8 \%$ \\
& $50-60$ & 20 & $17.2 \%$ \\
\multirow{4}{*}{ BMI } & Underweight & 3 & $15.5 \%$ \\
& Normal & 72 & $2.6 \%$ \\
& Overweight & 33 & $62.1 \%$ \\
& Obese & 8 & $28.4 \%$ \\
\hline
\end{tabular}

Table-2: Demographic data of the patients $(\mathrm{n}=$ ?)

\begin{tabular}{lllll}
\hline Parameters & Mean & SD & Minimum & Maximum \\
\hline Age & 44.46 & 14.68 & 18.00 & 88.00 \\
Weight & 68.75 & 13.23 & 31.00 & 125.00 \\
Height & 167.23 & 6.48 & 150.00 & 192.00 \\
BMI & 24.53 & 4.25 & 13.78 & 42.25 \\
\hline
\end{tabular}

Table-3: Parameters studied among patients for predicting frequent kidney and urinary tract stones

\begin{tabular}{|c|c|c|c|c|c|}
\hline \multicolumn{2}{|c|}{ Parameters } & \multirow{2}{*}{$\frac{\text { Mean }}{1655 \cdot 72}$} & \multirow{2}{*}{$\frac{S D}{569.47}$} & \multirow{2}{*}{$\begin{array}{l}\text { Minimum } \\
200.00\end{array}$} & \multirow{2}{*}{$\begin{array}{l}\text { Maximum } \\
4059.00\end{array}$} \\
\hline First & vol:24h & & & & \\
\hline 24 hours & $\mathrm{Cr}: 24 \mathrm{~h}$ & 1241.89 & 390.95 & 272.00 & 2760.00 \\
\hline & $\mathrm{Ca}: 24 \mathrm{~h}$ & 215.59 & 136.49 & 50.00 & 850.00 \\
\hline & $\mathrm{Mg}: 24 \mathrm{~h}$ & 67.41 & 30.01 & 1.40 & 153.00 \\
\hline & U.acid : $24 \mathrm{~h}$ & 394.47 & 157.39 & $5 \cdot 30$ & 870.00 \\
\hline & $\mathrm{ox}: 24 \mathrm{~h}$ & 6.67 & 7.48 & 0.14 & 61.00 \\
\hline & citrate: $24 \mathrm{~h}$ & 547.89 & 358.25 & 153.00 & 1722.00 \\
\hline & $\mathrm{p}: 24 \mathrm{~h}$ & 543.43 & 213.47 & 168.00 & 1080.00 \\
\hline & $\mathrm{Na}: 24 \mathrm{~h}$ & 182.60 & 78.14 & 38.60 & 432.00 \\
\hline & $\mathrm{K}: 24 \mathrm{~h}$ & 68.07 & 32.83 & 25.00 & 219.00 \\
\hline & $\mathrm{Cl}: 24 \mathrm{~h}$ & 125.09 & 61.48 & 30.00 & 342.00 \\
\hline & urea:24.1 & 19.48 & 5.49 & 10.50 & 39.00 \\
\hline \multirow{12}{*}{$\begin{array}{l}\text { Second } \\
\mathbf{2 4} \text { hours }\end{array}$} & vol : $24 \mathrm{~h}-1$ & 1677.16 & 545.83 & 500.00 & 5500.00 \\
\hline & $\mathrm{Cr}: 24 \mathrm{~h}$ & 1252.68 & 477.82 & 19.60 & 4000.00 \\
\hline & $\mathrm{Ca}: 24 \mathrm{~h}$ & 219.75 & 143.98 & 18.00 & 737.00 \\
\hline & $\mathrm{Mg}: 24 \mathrm{~h}$ & 66.03 & 33.41 & 0.01 & 156.00 \\
\hline & U.acid : $24 \mathrm{~h}$ & 434.41 & 180.01 & 86.00 & 1144.00 \\
\hline & ox: $24 \mathrm{~h}$ & 15.23 & 70.27 & 0.10 & 594.00 \\
\hline & citrate $: 24 \mathrm{~h}$ & $533 \cdot 36$ & 346.30 & $3 \cdot 70$ & 1856.00 \\
\hline & $\mathrm{p}: 24 \mathrm{~h}$ & 550.23 & 235.87 & 180.00 & 2200.00 \\
\hline & $\mathrm{Na}: 24 \mathrm{~h}$ & 194.78 & 116.83 & 12.00 & 1038.00 \\
\hline & $\mathrm{K}: 24 \mathrm{~h}$ & 68.99 & 42.39 & 23.00 & 320.00 \\
\hline & $\mathrm{Cl}: 24 \mathrm{~h}$ & 114.75 & 70.18 & $17 \cdot 50$ & 425.00 \\
\hline & urea:24.2 & 19.01 & 4.87 & 10.50 & $34 \cdot 30$ \\
\hline
\end{tabular}

Stone analysis showed that $48(41.4 \%)$ samples were Ca-ox and 22 (19\%) samples were U.acid and 46 (39.7\%) samples were Ca-ox + U.acid. The average stone size was 10.93 \pm 16.07 $\mathrm{mm}$ and the minimum size was $5 \mathrm{~mm}$ whereas the maximum was of $55 \mathrm{~mm}$.

Table- 3 shows the mean of the variables $(\mathrm{pH}, 24$-hour urine volume, urinary phosphorus, urine creatinine, urinary calcium, urinary oxalate, urinary sodium, urinary uric acid, urinary urea, urinary magnesium, urinary chlorine, urinary citrate, and urinary potassium) among frequent kidney and urinary tract stone patients.

Table-3: Parameters studied among patients for predicting frequent kidney and urinary tract stones

\begin{tabular}{|c|c|c|c|c|c|}
\hline Parameter & B & Sig. & OR & \multicolumn{2}{|c|}{ Lower Upper } \\
\hline (Intercept) & 3.059 & .000 & 21.313 & 11.978 & 37.924 \\
\hline $\begin{array}{l}\text { sex }=\text { male } \\
\text { sex=Female }\end{array}$ & .110 & .100 & 1.117 & .979 & 1.274 \\
\hline age $=>30$ & -.430 & .000 & .651 & .541 & .783 \\
\hline age $=30-40$ & -.383 & .000 & .682 & .569 & .817 \\
\hline age $=40-50$ & -.386 & .000 & .680 & .574 & .806 \\
\hline $\begin{array}{l}\text { age }=50-6 o \\
\text { age }=>60\end{array}$ & -.230 & .013 & .794 & .662 & .954 \\
\hline $\mathrm{BMI}=>18.5$ & -.972 & .000 & .378 & .223 & .643 \\
\hline $\mathrm{BMI}=18 \cdot 5^{-25}$ & -.161 & .145 & .851 & .685 & 1.057 \\
\hline $\mathrm{BMI}=25-30$ & -.306 & .014 & .736 & .577 & .939 \\
\hline $\mathrm{BMI}=>30$ & & & & & \\
\hline vol :24h=Normal & -.017 & .837 & .983 & .837 & 1.155 \\
\hline $\mathrm{Cr}: 24 \mathrm{~h}=$ Normal & .313 & .010 & 1.368 & 1.078 & 1.736 \\
\hline Ca $: 24 \mathrm{~h}=$ Normal & -.309 & .000 & .734 & .642 & .839 \\
\hline $\begin{array}{l}P: 24 \mathrm{~h}=\text { Normal } \\
O x: 24 \mathrm{~h}=\text { Normal }\end{array}$ & .391 & .005 & 1.478 & 1.125 & 1.942 \\
\hline $\mathrm{Na}: 24 \mathrm{~h}=$ Normal & -.164 & .029 & .849 & .732 & .983 \\
\hline U.acid $: 24 \mathrm{~h}=$ Normal & -.012 & .891 & .988 & .838 & 1.166 \\
\hline Mg :24h=Normal & -.210 & .165 & .810 & .602 & 1.090 \\
\hline Citrate $: 24 \mathrm{~h}=$ Normal & -.011 & .875 & .989 & .862 & 1.134 \\
\hline $\mathrm{Cl}: 24 \mathrm{~h}=$ Normal & -.183 & .195 & .833 & .631 & 1.099 \\
\hline $\mathrm{K}: 24 \mathrm{~h}=$ Normal & .388 & .005 & 1.473 & 1.121 & 1.936 \\
\hline Urea $: 24 \mathrm{~h}=$ Normal & .052 & .399 & 1.053 & .934 & 1.187 \\
\hline
\end{tabular}

Table-4 shows the results of Poisson Regression of biochemical factors ( $\mathrm{pH},: 24$-hour urine volume, urinary phosphorus, urine creatinine, urinary calcium, urinary oxalate, urinary sodium, urinary uric acid, urinary urea, urinary magnesium, urinary chlorine, urinary citrate, and urinary potassium), age, gender and BMI in predicting frequent kidney and urinary tract stones among patients. The results of Poisson Regression showed that none of these factors can significantly predict the frequent occurrence of kidney and urinary tract stones in patients.

Clinically, the possibility of frequent kidney and urinary tract stones in patients ranging from $30-40$ and $40-$ 50 are respectively 1.36 and 1.22 times higher. In addition, this possibility in patients with abnormal magnesium is 1.25 times higher.

\section{Discussion:}

Kidney stone disease is a multifactorial illness and many 
factors such as genetic, biochemical and epidemiologic factors are involved in the development of this disease. Internal factors (genetics, age, and gender) and external factors (geographical environment, climate, water consumption, diet and occupation) are effective factors in the formation of stone (Fouladi et al., 2012; Zayid Al-Risi et al., 2014). Therefore, this study was conducted to predict the effective factors in the recurrence of kidney and urinary tract stones based on demographic information and biochemical factors. Our results advocated that $52.8 \%$ of patients suffering from kidney stone were over 40 years old and the remaining was less than 40 years old. The majority of patients suffering from kidney stone and ureter stone in the United States were 50 and 46 years old respectively (Kim et al., 2001). The data analysis and the result of Poisson Regression showed that none of the demographic factors such as age, gender, and BMI can predict the frequent occurrence of kidney and urinary tract stones in patients. Fouladi et al. (2012) established the relationship between Types of Urinary Stones and their Risk Factors in Patients Visiting Health Centers, the BMI of all patients was reported $3.83 \pm 25.80$ and no significant difference was found between the BMIs of patients suffering from different kinds of urinary stones. As per Siener et al. (2004), BMI and 24-hour urine parameters showed that the concentration of uric acid and serum creatinine is directly related to the increase in BMI. BMI was also associated with a direct increase in the formation of kidney stones. Sarica et al. (2008) stated that obesity increases the ingredients of stones. Although the incidence of kidney stone has been reported more frequent in male compared to female patients, the result of regression analysis of the present study did not confirm this statement. Noshad et al. (2014) reported that 65 out of 200 patients suffering from kidney stone were male whereas Healy et al. (2013) done the assessment of the stone metabolism through 24 -hour urine collection and reported that $52 \%$ of the patients were male. In a study by Moghaddas et al. (2015) the effect of the type and amount of liquid consumption on kidney stones increased BMI and male gender was referred to as the risk factors for Urinary Stones. Walker et al. (2013) investigated the effect of age and gender on the stone formation factors. In their study, male to female ratio was 2.43 to 1 and the mean age was 49 thus the risk factors for men and women were different and varied with aging. Based on the clinical results of the present study, the possibility of frequent kidney and urinary tract stones in patients ranging from $30-$ 40 and 40-50 were respectively 1.36 and 1.22 times higher. Thus, the possibility of frequent stone formation increases at ages 30-40. The result of Poisson Regression showed that no biochemical parameters $(\mathrm{pH}, 24$-hour urine volume, urinary phosphorus, urine creatinine, urinary calcium, urinary oxalate, urinary sodium, urinary uric acid, urinary urea, urinary magnesium, urinary chlorine, urinary citrate, and urinary potassium) can significantly predict the frequent occurrence of kidney and urinary tract stones in patients. In addition, this possibility in patients with abnormal magnesium is 1.25 times higher.

Magnesium has been reported to play a preventive role in the formation of kidney stones (Tiselius, 2005). Urine magnesium decreases calcium oxalate urinary saturation by increasing urinary $\mathrm{pH}$ and citrate (Khan \& Hackett, 1993). Higher levels of magnesium in the male group as compared to the control group were also evidenced (Curhan et al., 2001; Curhan \& Taylor, 2008). Therefore, the protective role of magnesium in preventing frequent kidney stones is well established.

Conclusively, on the basis of regression analysis, it could be stated that none of these factors (to demographic information (demographic and/or biochemical factors) can predict the formation of frequent kidney stones. Thus, such studies can be done at longer intervals as prospective studies to achieve better results.

\section{Acknowledgment:}

We would like to thank the Clinical Research Development Unit of Peymanieh Educational and Research and Therapeutic Center of Jahrom University of Medical Sciences for providing facilities to this work

\section{References:}

Basiri, A., Shakhssalim, N., Khoshdel, A.R. \& Naghavi, M.(2009): Regional and seasonal variation in the incidence of urolithiasis in Iran: a place for obsession in case finding and statistical approach. Urol. Res., 37(4):197-204.

Basiri, A., Shakhssalim, N., Khoshdel, A.R., Ghahestani, S.M. \& Basiri, H.(2010): The demographic profile of urolithiasis in Iran: a nationwide epidemiologic study. Int Urol Nephrol., 42(1):119-126.

Curhan, G.C., Taylor, E.N. (2008): 24-h uric acid excretion and the risk of kidney stones. Kidney Int., 73(4):489-496.

Curhan, G.C., Willett, W.C., Speizer, F.E. \& Stampfer, M.J. (2001): Twenty-four-hour urine chemistries and the risk of kidney stones among women and men. Kidney Int., 59(6):22902298.

Fouladi, N., Alimohamadi, H., Hosenkhani, A., Amani, F. \& Ghoshadehroo, R. (2012): Relationship between types of urinary tract stones and it's probably risk factors in patients referred to therapeutic-surgery centers in ardabil city. $L$ Ardabil Univ. Med. Sci., 12(1):59-67.

Giannossi, M. L., Summa, V. \& Mongelli, G. (2012): Trace element investigations in urinary stones: A preliminary pilot case in Basilicata (Southern Italy). J. Trace Ele. Med. Biol., 27(2):9197.

Healy, K.A., Hubosky, S.G. \& Bagley, D.H. (2013): 24-hour urine collection in the metabolic evaluation of stone formers: is one study adequate?. Endourol., 27:374-378.

Khan, S.R. \& Hackett, R.L. (1993): Hyperoxaluria, enzymuria and nephrolithiasis. Contrib. Nephrol., 101:190-193.

Kim, H., Cheigh, J.S. \& Ham, H.W. (2001): Urinary stone following renal transplantation. Korean J. Intern. Med., 16(2):118-122. 


\section{ORIGINAL ARTICLE}

Moghaddas, F., Yousef i, F., Bagheri, F., Mohammadi, M., Mahdian Arefi, F.,Beikmohammadi, A. \& Emamian, M.H. (2015): The effect of the amount and type of liquid intake on kidney calculi: a case-control study. Iranian J. Epidemiol., 11(2):54-6o.

Morgan, M.S. \& Pearle, M.S.(2016): Medical management of renal stones. Brit Med.J., 352:i52.

Nicoletta, .A.\& Lande, M.B. (2006): Medical evaluation and treatment of urolithiasis. Pediatr. Clin. North Am., 53(3):479491.

Noshad, H., Ahmadpour, F., Soltanpour, B.\& Ghojazadeh. M. (2014): Study of renal stones complications in 2oopatients in Tabriz, Iran. J.Anal. Res. Clin. Med., 2(4):187-192.

Pak, C.Y., Peterson, R.\& Poindexter, J.R.(2001): Adequacy of a single stone risk analysis in the medical evaluation of urolithiasis. L. Urol., 165(2):378-381.

Pearle, M.S., Goldfarb, D.S., Assimos, D.G., Curhan, G., DenuCiocca, C.J., Matlaga, B.R., Monga, M., Penniston, K.L., Preminger, G.M., Turk, T.M.T., White, J.M. (2014): Medical management of kidney stones: AUA guideline. Pub. by: American Urological Association Education and Research, Inc. P. 26.

Sarica, K., Altay, B. \& Erturhan, S. (2008): Effect of being overweight on stone-forming risk factors. Urol., 71(5):771-774.
Ambient Science, 2019: Vol. 06h(1); 36-39 DOI:10.21276/ambi.2019.06h.1.0a08

Siener, R., Glatz, S., Nicolay, C. \& Hesse A. (2004): The role of overweight and obesity in calcium oxalate stone formation. Obes. Res., 12(1):106-113.

Soucie, J.M., Coates, R.J., McClellan, W., Austin, H. \& Thun, M. (1996): Relation between geographic variability in kidney stones prevalence and risk factors for stones. Am. I. Epidemiol., 143(5):487-495.

Tiselius H-G. (2005): Aetiological factors in stone formation, p. 1201-1223. In: Davison A.M, Cameron, S.J., Grunfeld, J-P., Kerr, D.N., Ritz, E., Winearsl, C.G. (eds.), Oxford Textbook of Clinical Nephrology. 3rd ed. Pub by: Oxford University Press.

Tiselius, H. G. (2003): Epidemiology and medical management of stone disease. BJUInt., 91(8):758-767

Trinchieri, A. (2008): Epidemiology of urolithiasis: an update. Clin Cases Miner Bone Metab., 5(2):101-106

Walker, V., Stansbridge, E.M. \& Griffin, D.G. (2013): Demography and biochemistry of 2800 Patients from a renal stones clinic. Ann. Clin. Biochem., 50(Pt 2):127-139.

Zayid Al-Risi, A.O., Ali, M.N. \& Ahuja, A.(2014): Study on prevalence and management of renal stones among Omani inpatients at Sohar hospital. Sch.J.Appl. Med. Sci., 2(1A):22-33. 